\title{
Influencia del éxito deportivo en la cobertura del deporte femenino español: los Juegos Olímpicos de Londres 2012 y Río 2016
}

\section{The influence of sporting success on the sports coverage of Spanish women: the London 2012 and Rio 2016 Olympic Games}

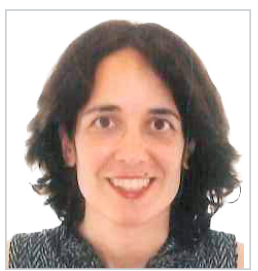

Begoña Sanz Garrido. Licenciada en Periodismo y doctora en Comunicación por la Universidad de Navarra. Desde 2001 ejerce como profesora e investigadora en la Facultad de Ciencias Sociales y Humanas de la Universidad de Deusto. Pertenece al equipo de investigación Género y Medios de Comunicación, con el que ha trabajado en el estudio de la representación mediática de las mujeres en relación con diversos temas: violencia de género, empresa, política, deporte y envejecimiento. Como resultado de esas investigaciones ha publicado diversos artículos y es coautora de libros como: Tratamiento de la violencia de género en la prensa vasca (2006); Dirigir en femenino (2009); Representaciones de las mujeres políticas en la prensa (2012), Las mujeres deportistas en la prensa: los Juegos Olímpicos de Londres 2012 (2015) Antes y después de los Mass Media (2016) y Representaciones artísticas y sociales del envejecimiento (2018).

Universidad de Deusto, España

begona.sanz@deusto.es

ORCID: 0000-0002-9471-8288

Recibido: 24/02/2020 - Aceptado: 21/07/2020

Resumen:

El éxito deportivo influye positivamente en el ánimo colectivo de un país y en el reforzamiento de su identidad nacional. Esta es una de las razones por las que existe correspondencia entre las expectativas de triunfo depositadas en determinados/as deportistas y el seguimiento social e informativo que se hace de ellos/as. Las atletas españolas en Londres 2012 y Río 2016 consiguieron más medallas que los representantes masculinos. Este estudio analiza si estos logros favorecieron su mayor cobertura mediática, si se narraron en clave de orgullo nacional, si se presentaron a las atletas como referentes deportivos y si los valores que se destacaron de ellas se corresponden con los asociados a la práctica deportiva ejemplar. Para ello se realiza un análisis de contenido y una lectura crítica de los suplementos especiales sobre esos Juegos Olímpicos publicados por el diario deportivo español Marca. Los resultados revelan que, en el tratamiento mediático del deporte femenino, prima el valor informativo de la nacionalidad española de la atleta por encima del de sus logros deportivos. Y que, aunque su actuación se asocie a valores como el esfuerzo o la mentalidad ganadora, los modelos inspiradores en el deporte siguen estando encarnados por ellos.

Palabras clave:

Juegos Olímpicos; deporte femenino; teoría crítica feminista; éxito deportivo; referente deportivo; orgullo nacional.
Received: 24/02/2020 - Accepted: 21/07/2020

Abstract:

Sporting success has a positive impact on the collective mood of a country and helps to strengthen its national identity. This is one reason why there is a correlation between the expectations for certain athletes to win and the social and media follow-up of them. The Spanish female athletes in London 2012 and Rio 2016 won more medals than the male athletes. This study analyses whether these achievements favoured greater media coverage, if they were narrated in terms of national pride, if female athletes were represented as sports references and whether the values that were highlighted correspond to those associated with exemplary sports practice. To examine such results, content analysis and critical reading of these Olympic Games' special supplements published by the newspaper Marca is carried out. The results reveal that the news value of the athlete's Spanish nationality prevails over her sporting achievements in the media coverage of women's sport. Although women's performance is associated with effort or a winning mentality, the inspiring role models in sport continue to be male athletes.

Keywords:

Olympic Games; women's sport; critical feminist theory; sporting success; sports model; national pride.

Cómo citar este artículo:

Sanz Garrido, B. (2020). Influencia del éxito deportivo en la cobertura del deporte femenino español: los Juegos Olímpicos de Londres 2012 y Río 2016. Doxa Comunicación, 31, pp. 131-151. 


\section{Introducción}

Los logros deportivos influyen en el estado de ánimo colectivo de la población de un país, el reforzamiento de su identidad nacional y contribuyen, en ocasiones, a convertir a los/las atletas en referentes y modelos deportivos. Como indican Fernández y Bassani (2008, p. 46), la actividad deportiva se encuentra hoy "en el centro de las identidades nacionales", y las justas deportivas se han convertido en un fenómeno que tiene un impacto profundo en la construcción de la confianza social, tanto colectiva como individual, de las naciones y sus habitantes (Humanez, 2014). Tal y como escribiría al finalizar la cita olímpica de Londres 2012 el entonces presidente de España, Mariano Rajoy, en una columna de opinión publicada por Marca: "Los deportistas españoles deben saber que su esfuerzo personal, sus horas de entrenamiento y de superación, han servido para dar satisfacción a todo un país”(Marca, 12/08/2012 p. 11).

La difusión masiva que los medios hacen de las gestas deportivas contribuye a reforzar este papel del deporte como aglutinante social y fuente de confianza nacional (González-Ramallal, 2008; Meneses, 2008) y consigue que el éxito deportivo logrado por unos/as deportistas se traspase al país al que representan (Caspistegui, 2012) y estimule la práctica de ciertos deportes entre su ciudadanía (Méndez-Giménez, Fernández-Rio, González, 2008). Como indica Moragas (2000), “los mass media contribuyen a incrementar notablemente el triunfalismo nacionalista de las victorias". Durántez (2012) afirma a este respecto que:

A través de la prensa y demás medios de comunicación y publicidad, se da notorio énfasis y trascendencia al medallero olímpico, donde se constatan toda una serie de resultados y clasificaciones a tenor del tipo de medalla conseguidas y por las que, incluso omitiendo los nombres de los atletas que han ganado, se llega a la absurda conclusión de que tal o cual país ha ganado los Juegos (pp. 351-352).

Partiendo de esta premisa de que el deportista de élite, ayudado por los medios de comunicación, se convierte en fuente de orgullo para su país y en referente deportivo cuando gana en eventos internacionales, nuestro interés investigador se fija en los Juegos Olímpicos de Londres 2012 y de Río de Janeiro 2016 con el objetivo de analizar si tal premisa se cumple también con las atletas.

Se ha elegido estas citas olímpicas porque en Londres 2012 (considerados como "los juegos de las mujeres" pues participaron 4.676 -el 46\% de los atletas-, en todos los deportes, y todas las delegaciones contaron con una representante femenina), las deportistas españolas lograron un éxito tan inesperado como lo fue el fracaso de los representantes masculinos. La selección española masculina de fútbol, que partía como candidata al oro, fue eliminada en la primera fase. Y los atletas obtuvieron 6 medallas (la mitad de las conseguidas en Pekín 2008) mientras que ellas consiguieron 11 (en Pekín 2008 habían logrado 4). Por primera vez, las representantes españolas alcanzaban una presencia mayor en el medallero que los hombres. Y esta superioridad se repetiría -aunque con una diferencia menor (8/9)- en Río 2016.

La investigación se enmarca en la teoría crítica feminista. Tal como señalan Kane y Maxwell (2011:203), con respecto a la cobertura de los medios deportivos, un teórico crítico se pregunta de quién son las voces, perspectivas y experiencias que se consideran válidas y dominantes; y quiénes son considerados los atletas más importantes al analizar a quién le prestan atención y credibilidad los medios de comunicación (Alvesson \& Willmott, 2003). Como un subconjunto de la teoría crítica, la teoría crítica feminista supone que la sociedad se estructura en torno a una serie de relaciones de poder no 
equitativas mediante las cuales las mujeres son sistemáticamente devaluadas y marginadas (Birrell, 2000; Hoeber, 2007). Si nos referimos a la cobertura mediática de las deportistas, esto se traduce en una infrarrepresentación cuantitativa y cualitativa en los medios.

El deporte femenino siempre ha tenido una menor cobertura en los medios que el masculino (Cooky, Ducan \& Messner, 2005; Crouse, 2013; Fink \& Kensicki, 2002; Grau, Roselli \& Taylor, 2007; Messner \& Hextum, 2013). Sainz de Baranda (2013), en el estudio que realiza de la prensa deportiva española durante el periodo 1979-2010, constata que la información referida al deporte femenino no supera el 4\% en ninguno de los años analizados. En el 2015, la situación es muy similar: el informe Presencia y tratamiento del deporte femenino en la prensa generalista vasca y en periódicos de información deportiva, elaborado por la dirección de Juventud y Deporte del Gobierno Vasco, confirma que las informaciones que hacen referencia en exclusiva al deporte femenino suponen el 4,96\% de lo publicado en esos medios.

No obstante, el hecho de que en unos Juegos Olímpicos compitan las mejores atletas de todas las disciplinas deportivas de cada país por conseguir proclamarse campeona olímpica y/o batir el récord vigente hace posible pensar en un incremento notable de la cobertura mediática de las pruebas femeninas. Y si, como se recoge en las primeras líneas de este artículo, el éxito logrado en las competiciones deportivas influye en el espíritu y confianza nacionales, se presupone que existirá una correspondencia entre la cobertura informativa que se hace de ciertos deportes y deportistas y la posibilidad de que estas obtengan buenos resultados. Es decir, será más numerosa la información que ofrecen los medios de las atletas de su país que logren medallas que de las que no.

Cualitativamente, la imagen mediática difundida sobre las mujeres como atletas también resulta infravalorada respecto a la de sus homólogos masculinos, asociándose más a estereotipos de su faceta como mujer que a valores como deportista (Alfaro, Bengoechea y Vázquez, 2010; Angulo, 2007; Bissell \& Duke, 2007; Daniels, 2009; Giuliano, Turner, Lundquist \& Knight, 2007; Jones, 2006; Kim, Walkosz, \& Iverson, 2006; Knight \& Giuliano, 2001; Lallana, 2005; Mateos, Martínez \& Rodríguez, 2005; Sanz, 2012; Shaller, 2006).

En el contexto descrito de una actuación deportiva exitosa a nivel de resultados (medallas) realizada por las deportistas españolas en Londres 2012 y Río 2016, y desde una lectura crítica feminista, nos planteamos los siguientes interrogantes de investigación:

1. ¿Los éxitos logrados por el deporte femenino español en esas citas olímpicas fueron narrados en clave de orgullo nacional?

2. ¿Los valores que se destacaron de las deportistas se corresponden con los asociados tradicionalmente a los modelos de conducta deportiva como son el esfuerzo, el sacrificio, la superación personal, etc.?

3. ¿El medallero obtenido en Londres 2012 influyó positivamente en el tratamiento informativo cuantitativo y cualitativo que se dio a las atletas en la siguiente cita olímpica, la de Río 2016 ? 


\section{Metodología}

Para contestar estos interrogantes, en la presente investigación se va a utilizar como muestra de estudio la información publicada por el periódico deportivo español Marca. Su elección responde a la posición que ocupa el diario en el ranquin de lectores. Marca es referente de la prensa deportiva en España y líder de audiencia desde hace décadas; y lo era en 2012 y 2016, años de nuestra investigación. Los datos ofrecidos por el Estudio General de Medios demuestran que, a lo largo de los años, la audiencia de Marca ha ido progresivamente disminuyendo, al igual que la del resto de cabeceras de prensa deportiva impresa en España. Pero, aun así, sus lectores representan la mitad de la audiencia de la prensa deportiva, superando los datos de As, Sport y Mundo Deportivo juntos. Marca registró en el periodo febrero-noviembre de 2012 una media de 3.011.000 lectores/día y en el mismo periodo de 2016 de 2.165.000 lectores/día. Este liderazgo hace que, desde sus páginas, Marca pueda ejercer una gran influencia respecto a la imagen que se proyecta del deporte en general y, en concreto, de los Juegos Olímpicos y de la participación de las mujeres en ellos.

Nuestro análisis se centra en los suplementos especiales sobre los Juegos Olímpicos que publica Marca dentro de sus ejemplares: el Suplemento Juegos 2012 del 27 de julio al 13 de agosto de 2012 y El diario de los Juegos con la cabecera Marca. Juegos de la XXXXI Olimpiada Río 2016 del 2 al 23 de agosto de 2016. Este es, por tanto, el periodo de nuestro análisis: 27 julio-13 agosto de 2012 y 2-23 de agosto de 2016.

La metodología empleada combina técnicas cuantitativas y cualitativas como el análisis de contenido -técnica exploratoria y descriptiva destinada a formular, a partir de ciertos datos, inferencias reproducibles y válidas que puedan aplicarse a un contexto (Krippendorff, 2018) - y el análisis crítico del discurso (Van Dijk, 1999). Con el objetivo de comprobar qué interés informativo otorga Marca a las deportistas españolas al inicio de las dos citas olímpicas y si el éxito logrado por las mujeres en Londres 2012 influyó positivamente en la cobertura inicial que Marca da al deporte femenino en Río 2016, se hace una lectura crítica de los suplementos especiales que se publican en los días previos al inicio de los Juegos Olímpicos de 2012 y 2016.

Posteriormente, se estudia, a través de un análisis cuantitativo de los suplementos y una lectura crítica de sus portadas, si el valor noticia de la procedencia española de las deportistas resulta prioritario para Marca, por encima del valor noticia del éxito deportivo -los valores noticia son aquellos criterios que influyen en la selección de un hecho como noticia publicable, es decir, aquellos valores que otorgan interés informativo a un acontecimiento- y cuál es el tema destacado en las informaciones sobre las atletas.

Para realizar este análisis cuantitativo se han registrado las unidades informativas en las que las mujeres deportistas -que compiten de forma individual o en equipo- constituyen el sujeto informativo de la cabecera de titulares, bien al ser nombradas directamente, "Carolina Marín también es la reina de las audiencias"(26/8/2016 p. 14) o indirectamente, "Es ahora o ahora " (20/08/2016 p. 17), titular que hace referencia al equipo español de gimnasia rítmica. El protagonismo de las mujeres puede ser en exclusiva ("Brilla Mireia" 8/08/2016 portada) o compartiendo protagonismo con los deportistas masculinos ("El atletismo se recupera" 22/08/2016 p. 4, titular de una noticia en la que se habla sobre la actuación de Ruth Beitia y Orlando Ortega). En nuestro análisis nos centraremos en las unidades informativas en las que las mujeres deportistas adquieren el protagonismo del titular en exclusiva. 
Y se considera unidad informativa a 1) los textos de cualquier género informativo publicados por el diario, conformados por cabecera de titulares, cuerpo de texto y fotografías o no; 2) los titulares sin acompañamiento de texto ni imágenes que el diario publica en la portada de los suplementos y 3) las fotonoticias o titulares acompañados solo por una fotografía.

En total se han registrado 244 unidades informativas de Londres 2012 (183 corresponden a deportistas nacionales y 61 a internacionales) y 218 unidades informativas de Río 2016 (147 de deportistas nacionales y 71 de internacionales). De cada una de estas unidades informativas se recogen una serie de datos para cuyo tratamiento cuantitativo se ha utilizado una hoja de cálculo.

De todas las variables utilizadas para la recogida de datos, para este artículo se han empleado las siguientes: para la identificación de la unidad informativa en su contexto periodístico se emplean las categorías de Título, Subtítulo, Fecha de publicación y Número de página. Para identificar a las deportistas se usan las categorías de Nombre completo, Nacionalidad, con las variables Deportista Nacional/Deportista extranjera; Disciplina deportiva, con las variables correspondientes a todas las disciplinas según el listado establecido por el COI (Comité Olímpico Internacional). Y para comprobar cuál es el tema prioritario que se aborda en las unidades informativas se registra la categoría Tema con las siguientes variables: Éxitos, fracasos, clasificación y medallas/ Características físicas y mentales de la deportista/ Preparación y organización del equipo/ Cuestiones personales/ Prueba concreta/ Rivalidades directas/ Aspectos económicos del deporte de élite/ Carrera deportiva de la deportista/ Villa olímpica: el día a día/ Salud (dopaje, etc.) / Juegos Olímpicos: organización/ Juegos Olímpicos: cobertura mediática.

Finalmente, se realiza una lectura crítica de la cobertura dada a la participación del equipo femenino de Match Race en Londres 2012 y a la jugadora de bádminton Carolina Marín en Río 2016. El objetivo es comprobar si hay diferencia entre ambas coberturas debido a las expectativas de triunfo que se tenían sobre ellas: las primeras apenas eran conocidas y su medalla de oro fue una sorpresa mientras que sobre Marín se tenían puestas todas las esperanzas de que ganara el oro; interesa ver qué cualidades se destacan de ellas y si se realizan las crónicas en clave de orgullo nacional.

\section{Cobertura realizada los días previos al comienzo de los Juegos Olímpicos}

Las deportistas españolas obtuvieron representación en el medallero olímpico a partir de los Juegos Olímpicos de Barcelona 1992, con 4 oros (Miriam Blasco y Almudena Muñoz en judo; el dúo Theresa Zabell y Patricia Guerra en vela y la selección femenina de hockey hierba), 3 platas (Carolina Pascual en gimnasia, en dobles tenis Arantxa Sánchez Vicario y Concepción Martínez, y en vela Natalia Vía-Dufresne), y 1 bronce en tenis ganado por Arantxa Sánchez Vicario.

La organización de estos juegos por parte de España supuso un incremento en la participación de las deportistas: de 31 mujeres en los Juegos de Seúl de 1988 a 128 en Barcelona 1992. Hasta entonces, la participación de mujeres españolas en los Juegos Olímpicos del siglo XX había sido casi nula. En París 1900 compitieron por primera vez cuatro mujeres y hubo que esperar hasta Roma 1960 para ver de nuevo a mujeres deportistas españolas en unos Juegos Olímpicos, con 11 participantes. A partir de Barcelona 1992, el número de mujeres olímpicas españolas no ha bajado de 90 y su presencia ha ido aumentando, y disminuyéndose la diferencia de participación respecto a los hombres; así, en los Juegos Olímpicos de Río 2016, en el equipo español han participado 143 mujeres y 163 hombres. 
Como se acaba de indicar, Barcelona 1992 supuso un punto de inflexión respecto a la participación femenina en unos Juegos Olímpicos, y ello tuvo su correlación en el medallero español: las deportistas consiguieron 8 medallas. Tras Barcelona 1992 y hasta Londres 2012, la tendencia en el medallero español era de mantenimiento de la presencia femenina en él, pero en una proporción significativamente inferior respecto a los hombres: Atlanta 1996 (6/10), Sydney 2000 (4/7), Atenas 2004 (4/13) y Pekín 2008 (4/12).

Esta tendencia no hacía prever lo que ocurriría en los Juegos Olímpicos de Londres 2012. Las atletas españolas, por primera vez, conseguirían más medallas que los hombres: 11, mientras ellos obtuvieron 6.

Marca, el 27 de julio de 2012, día en el que se iba a celebrar la ceremonia de inauguración de los Juegos, publica el suplemento especial "Ready, steady, go" en el que hace referencia a la sede olímpica, Londres, y, principalmente, a los/las deportistas sobre los que se tenía expectativas de que pudiesen lograr medalla y / o batir récord. El análisis del contenido de este suplemento evidencia, por un lado, la importancia informativa que se otorga al éxito deportivo y, por otro, cómo al inicio de la competición, las mujeres deportista españolas no son referentes deportivos para Marca, pero tampoco las atletas internacionales; es decir, el deporte femenino no acapara la atención del diario. Así se observa ya desde el subtítulo de la portada de este suplemento: "Gasol, Phelps o Bolt son algunos de los deportistas que en los próximos 15 días tratarán de batir récords en una de las ciudades más emblemáticas del mundo".

De las 16 páginas del suplemento 10 si descontamos las 6 páginas de publicidad la portada y las páginas principales se centran en informar textual y fotográficamente sobre la ÑBA, Pau Gasol, Michel Phelps, Yonan Blake, Usain Bolt, Asafa Powell, Tyson Gay, Roger Federer, David Ferrer y la selección brasileña masculina de fútbol. Solo en dos páginas, la 9 y la 14, se alude al deporte femenino en los últimos párrafos de las noticias; y de las 24 fotos en las que aparecen atletas, sólo 4 son de alguna deportista; y de estas, solo una es de atletas españolas: la que muestra las piernas por encima del agua del equipo femenino de natación sincronizada.

En el margen derecho de la página 9 se edita una columna con el titular "Favoritos a coronarse en la pista de atletismo", 8 fotografías y textos de los/as principales deportistas que se espera que obtengan medalla: 4 de ellos se refieren a mujeres deportistas no nacionales. Las deportistas españolas aparecen sólo en la página 14, la última página informativa del suplemento. En esta página en cinco breves textos se hace referencia a las posibilidades de triunfo de los/as representantes españoles, dedicándose sólo el titular de uno de ellos -"Sirenas de plata, certeza de podio"-a las atletas nacionales de la natación sincronizada (no hay equipo masculino de esta disciplina), quienes habían conseguido en la anterior cita olímpica de Pekín 2008 la medalla de plata en equipos y la de dúo con Andrea Fuentes y Genma Mengual.

La actuación de las deportistas españolas en Londres 2012 -consiguieron 11 medallas frente a las 6 de los representantes masculinos- y la progresiva mayor importancia mediática otorgada al deporte femenino pudieran hacer pensar que, al inicio de la siguiente cita olímpica de Río 2016, Marca otorgaría mayor cobertura informativa al deporte femenino español. Sin embargo, no fue así; las deportistas nacionales apenas acapararon espacio e imágenes, en un contexto de escasa cobertura del deporte femenino en general por parte del diario en los días previos al inicio de los Juegos. 
Esos días, Marca publica el suplemento El diario de los Juegos con los siguientes titulares: Oro puro (2 de agosto), Preparados (3 de agosto), Listos...(4 de agosto), iiiiYa!!!! (5 de agosto). Fotográficamente, la presencia de las deportistas tanto nacionales como internacionales resulta anecdótica:

Fig. 1. Número de fotografías publicadas $\mathrm{N}=$ deportistas nacionales $\mathrm{I}=$ deportistas internacionales

\begin{tabular}{|l|l|l|l|l|}
\hline & 2 de agosto & 3 de agosto & 4 de agosto & 5 de agosto \\
\hline Fotos hombres & 24 (N8 I16) & 16 (N13 I3) & 15 (N8 I7) & 14 (N9 I5) \\
\hline Fotos mujeres & 3 (N1 I2) & 4 (N3 I1) & 3 (N2 I1) & 5 (2N 3I) \\
\hline
\end{tabular}

Fuente: Elaboración propia

Incluso en escenas donde los/as deportistas no aparecen practicando un deporte sino desarrollando una actividad en la villa olímpica, el protagonismo absoluto es de ellos; estos son los pies de foto de esas imágenes en las que sólo aparecen hombres: "Selfi de los veteranos del baloncesto", "Nadal-Go en Río", "Deportistas españoles posan en Barajas antes de partir a Río", "Primera salida de la Villa” y “ El cura Lusek entre los jugadores italianos de vóley playa”.

En los textos publicados esos días, también aparecen muy pocas deportistas. El 2 de agosto, la portada y las páginas 2 y 3 son para el "Dream Team” de EE. UU.; las páginas 4 y 5 , para Rafa Nadal y David Ferrer; y la página 6 para Neymar y la selección de fútbol masculina de Brasil. Hasta la página 7 no aparece una deportista: la nadadora nepalí Singh, por ser la olímpica más joven y superviviente de un terremoto producido en Nepal en 2015; el foco informativo, por tanto, queda fuera del deporte. En la siguiente página, la contraportada, comparten protagonismo el halterófilo brasileño Fernando Reis y la balonmanista Eli Pinedo. Esta última responde al "Test de los Juegos”, realizado por Marca cada día a un/a deportista. En la cabecera de titulares de este test adquiere más importancia el atleta Usain Bolt que la propia deportista:

Titular: "Bailaría una samba con Usain Bolt"

Subtitular: Eli Pinedo, una de las 'guerreras' de España, querría "ser una estrella de rock en la otra vida”. A Río llega con ganas de coincidir con Usain Bolt, un ídolo.

En el suplemento "Preparados..." del 3 de agosto, la portada, página 2 y página 3 se dedican al futbol. El tratamiento fotográfico, infográfico y textual resulta cuantitativa y espacialmente equilibrado entre el fútbol femenino y el masculino. Un aspecto mejorable, no obstante, es el tratamiento androcéntrico (Vid. Alfaro, Bengoetxea y Vázquez, 2010, p. 24) que se da a la capitana de Brasil, Marta Vieria, a quien, para resaltar su valía la denominan la Pelé con faldas, siendo el futbolista el término de comparación y referente al que se le feminiza mediante la prenda de vestir "falda", cuando las futbolistas siempre juegan con pantalón corto. La futbolista comparte protagonismo en este suplemento con la nadadora siria Yusra Mardini, del equipo de refugiados, de la que se informa por un hecho no relacionado con su trayectoria deportiva: salvó la vida de 16 personas remolcando una lancha desde Turquía hasta Grecia. Y con la jugadora de baloncesto Alba Torrens, quien contesta el test de los Juegos; es la única deportista española a la que se hace referencia en el suplemento de ese día. En el del 4 de agosto sólo aparecen dos deportistas, Ruth Beitia y Mireia Belmonte, en el reportaje titulado “La 'medallitis' es el patrón de media" y otras tres en el dedicado a los atletas homosexuales que acuden a Río. Y en el suplemento del 5 de 
agosto, de nuevo sólo dos textos se dedican a ellas: uno sobre la balonmanista Darly Zoqbi y otro sobre la ÑBA femenina. Tal como se expone en el texto dedicado a la selección femenina de baloncesto, "El deporte femenino español fue el gran protagonista de los juegos de Londres (...). Sin embargo, los éxitos no han bastado para que las chicas puedan competir con los hombres en repercusión" (4/08/2016 p. 8).

\section{El valor noticia prioritario: la nacionalidad española de las deportistas}

En este apartado de la investigación nos planteamos comprobar qué valor noticia prima más para un periódico deportivo, como lo es Marca, a la hora de cubrir la actuación deportiva de las atletas en los Juegos Olímpicos: si su nacionalidad española o el éxito deportivo cosechado por la atleta, con independencia de la nacionalidad que tenga dicha deportista.

El primer dato que se obtiene tras el análisis cuantitativo de las unidades informativas registradas es que, en la información sobre Londres 2012, las deportistas españolas acapararon el 75\% (183) de las 244 unidades informativas dedicadas a las deportistas, tres veces más que las deportistas internacionales; en las 218 unidades informativas de Río 2016 también se otorga mayor cobertura a las deportistas nacionales que a las no españolas: 147 informaciones (67.4\%) frente a 71 $(32,6 \%)^{1}$.

Además, si en una prueba hay posibilidades de que una deportista española logre medalla, se informa antes y de forma más extensa sobre su actuación, aunque finalmente no haya logrado un puesto en el medallero, que de la medalla de oro conseguida en esa disciplina por una atleta internacional.

Ejemplificaremos esto con la cobertura que Marca realiza de la final de los $400 \mathrm{~m}$ estilos de natación, tanto en Londres 2012 como en Río 2016. En 2012, el espectacular triunfo que consigue la nadadora china Ye Shiwen, de tan solo 16 años, batiendo el récord mundial, ocupa una doble columna y una imagen de la página 5 del cuadernillo ("Shiwen Ye lanza la natación a un tiempo futuro", 29 de julio). La actuación de la nadadora Mireia Belmonte, que logra un octavo puesto, sin embargo, se recoge ya en la portada del suplemento a través de un titular: "Decepción. Mireia y el ciclismo, pobre arranque español”; y en el interior, en una crónica a toda página con dos fotografías, una de ellas a seis columnas: "Mireia encoge en la final olímpica" (29 de julio, p. 4).

En Río 2016, la nadadora española consigue la medalla de broce en esta prueba. Y con ello, de nuevo el protagonismo informativo en Marca: acapara la portada del diario, la portada del cuadernillo, con una foto a seis columnas y el titular "Brilla Mireia", la página 2 y tres columnas de la página 3 con un texto en el que se describen las cualidades de la nadadora y sus logros ("Es única", pp. 2 y 3, 8 de agosto) y una crónica de la remontada que realiza en los 50 últimos metros de la prueba.

1 El total de las unidades informativas dedicadas a las mujeres en Londres 2012 es superior a la de Rio 2016, por eso en el análisis realizado se ofrece, además de la cifra, el porcentaje que esta supone respecto al total. A la hora de valorar esta diferencia en el número de unidades informativas, hay que tener en cuenta la paginación de los suplementos: el editado en 2012 tiene una media de 28 páginas, y el del 2016, de 20 páginas. Esta menor paginación del suplemento de 2016 se debe, principalmente, al trasvase de lectores de la prensa deportiva impresa a la digital (Marca registró una pérdida de 846.000 lectores entre 2012 y 2016, según datos del EGM) y al descenso de inversión publicitaria en los medios impresos debido, en gran parte, a la crisis económica general que afectó a España y a esa disminución de lectores. 
La ganadora de esta final de los $400 \mathrm{~m}$ estilos, la húngara Katinika Hosszu, se impuso superando el increíble récord que Shiwen Ye había realizado en 2012. Pero, al igual que ella, no superó el protagonismo informativo de Mireia Belmonte en Marca, y tuvo que conformarse con una foto y un texto a tres columnas de la página 3 ("Más allá de la razón", p. 3, 8 de agosto).

La mayor importancia otorgada por Marca a nuestras deportistas también se pone de manifiesto por el lugar que la noticia ocupa dentro del periódico y por la ausencia o presencia en ella de elementos visuales (fotografías, gráficos), además de los textuales, lo que influye en que la noticia se convierta o no en el Centro de Impacto Visual (CIV) de la página, es decir, en la parte de la página que llama la atención del espectador de inmediato (García, 1983). En Londres 2012, como se puede observar en la Fig. 2, las deportistas españolas consiguen ser el CIV de seis de las portadas del cuadernillo al protagonizar la fotografía y titulares principales.

El protagonismo de las otras diez portadas del cuadernillo lo acapara el deporte masculino; las deportistas internacionales, por lo tanto, no consiguen ningún día que Marca les otorgue la máxima importancia informativa. Sí lo hacen los deportistas internacionales en cuatro portadas: el nadador norteamericano Michel Phelps en dos ocasiones, el nadador francés Angel Lochte en una portada, y en otra, la final de los 100 metros lisos y Usain Bolt. Y 6 veces los deportistas españoles: el equipo de fútbol, el judoca Sugoi Uriarte, los tenistas Feliciano López y David Ferrer, y la selección de baloncesto en tres ocasiones.

En Río 2016, las atletas españolas consiguen un mayor protagonismo en las portadas, siendo el CIV de la primera página en ocho ocasiones: dos veces la nadadora Mireia, una vez Mireia compartiendo portada con la piragüista Maialen Chorraut, una, Lidia Valentín (bronce en halterofilia), una, Carolina Marín (oro en bádminton) y dos Ruth Beitia (oro en salto de altura) y una portada compartida entre las selecciones femeninas de balonmano, baloncesto y la pareja de voleibol playa Liliana Fernández y Elsa Baquerizo. El mismo número de portadas acapara el deporte masculino, aunque a diferencia de Londres 2012, sólo en una ocasión un deportista internacional aparece en la fotografía principal de portada: Usain Bolt. Las otras siete portadas son para: 2 Rafa Nadal, 1 Nadal y Marc López, 1 el piragüista Marcus Cooper, 1 Saúl Craviotto y Cristian Toro de K2 200 y 1 Saúl Craviotto. Al igual que en Londres 2012, las deportistas internacionales no consiguen el protagonismo de la portada del cuadernillo Marca Río 2016. 
Fig. 2. CIV de las portadas de los cuadernillos

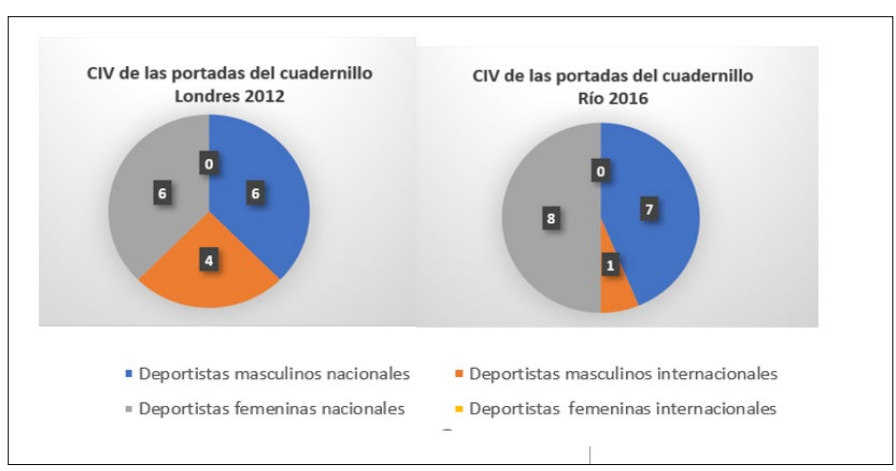

Fuente: Elaboración propia

Podemos observar, por lo tanto, que en la cobertura del deporte masculino no importa tanto la nacionalidad del deportista como el que este tenga atractivo para la audiencia por su trayectoria deportiva (caso de Usain Bolt y Michel Phelps) o por su actuación en esa cita olímpica. No es así en el deporte femenino: acapara el protagonismo de la portada sólo por tratarse de deportistas españolas. En la cobertura que Marca realiza del deporte femenino en las dos citas olímpicas, por lo tanto, la nacionalidad española de las atletas representa el criterio principal de jerarquización de las noticias, por encima del éxito deportivo. Como señala Moragas (2000:8) "el éxito popular y de audiencia del deporte se debe a la existencia de tres factores principales: la emoción, la espectacularidad y, sobre todo, la identidad".

Hemos analizado, también, en quién recae el protagonismo en los titulares de las portadas protagonizadas por las deportistas nacionales: si en ellas, con lo que se da relevancia a las atletas, o en el país al que representan, España, poniéndose de relieve el triunfalismo nacionalista de las victorias.

Como se puede observar en la cabecera de titulares de las portadas de los cuadernillos de Londres 2012

$Y$ una de bravas. Maialen Chorraut busca la segunda en piragüismo y de paso cambiar la tendencia del deporte español en Londres (2/08/2012).

Las damas primero. Silvia Navarro y Laura Ester, las guardametas de balonmano y waterpolo, enamoran Londres (3/08/2012).

El estanque dorado. El waterpolo femenino español hace historia al llegar a semifinales en su debut olímpico. (6/08/2012).

España rompe aguas. Alabau, Gómez Noya, las chicas de la sincro y las del waterpolo riegan nuestro mejor día en Londres (8/08/2012).

Como peces en el agua. España gana la medalla de bronce en natación sincronizada con una puesta en escena espectacular (11/08/2012).

Ellas son así. Las chicas del Elliot 6 dan el tercer oro a España y las del balonmano logran un broche histórico (12/08/2012).

en dos ocasiones el sujeto del titular o subtítulo que logra una victoria es España, con lo que el triunfo se hace extensivo a todo el país: "España gana la medalla de bronce en natación sincronizada..." (11/08/2012), "España rompe aguas" ((8/08/2012); en los del 2016, también en dos titulares: “España conquista dos oros en la piscina...” (12/08/2016) y “Es- 
paña pone un broche de oro a los juegos con las medallas de...” (22/08/2016), el sujeto al que se adjudica el logro de los triunfos es el país de las atletas. En los demás titulares publicados en los suplementos de 2012 y 2016, el protagonismo recae en las deportistas.

\author{
Son guerreras. El sector femenino dibuja esperanzas para España, que suma otro cuarto puesto con Castroviejo en ciclismo y un \\ quinto con Bernabéu en judo. (11/08/2016). \\ Brilla Mireia. Belmonte estrena el medallero tras una fantástica remontada que le lleva al bronce. La tiradora Fátima Gálvez, \\ cuarta por sólo un plato. (8/08/2016). \\ Agua bendita. España conquista dos oros en la piscina y las aguas bravas mientras que Nadal y López se meten en la final de \\ dobles y aseguran una más (12/08/2016). \\ Levanta España. Lydia Valentín logra la cuarta medalla de España en Río, en halterofilia, y Rafa Nadal se mete en las semifinales \\ del torneo individual (13/08/2016). \\ Triple corona. Carolina Marín conquista el sexto oro de España mientras el taekwondo sigue siendo un puntal: plata para \\ Calvo y bronce para Joel (20/08/2016). \\ El show final. España pone un broche de otro a los juegos con las medallas de Beitia, la rítmica, el baloncesto y Carlos Coloma \\ en mountain bike (22/08/2016).
}

Se alude a ellas por su nombre y apellido cuando participan en pruebas individuales o por parejas. Y si es un equipo, se hace referencia a él indicando la especialidad, el género y la nacionalidad del equipo (el waterpolo femenino español) o a través del término genérico "chicas” más su disciplina deportiva (las chicas de la sincro y las del waterpolo, las chicas del Elliot y las del balonmano), en el caso de los titulares de 2012. Este tratamiento condescendiente y paternalista a través del sustantivo "chica" no se otorga a los deportistas masculinos en ninguno de los titulares en los que se hace referencia a ellos; así, se alude al equipo de futbol masculino a través de "España” o al de baloncesto con España o "la ÑBA"; pero no se escribe "los chicos del baloncesto" o "los chicos del balonmano". En 2016, como podemos observar en los titulares de las noticias, Marca deja de utilizar esa forma no recomendada de referirse a las deportistas en esa cita olímpica. En lugar de decir "las chicas dan esperanzas a España”, el subtítulo de la portada del 11 de agosto engloba a la selección de balonmano y de baloncesto femeninas, y a la pareja de voleibol Liliana Fernández y Elsa Baquerizo a través del sujeto "el sector femenino"; la portada muestra a cada una de ellas en una fotografía y el párrafo de portada las nombra.

En cuanto a las fotografías de las deportistas en las portadas, son más numerosas aquellas en las que aparecen en acción en algún momento de la prueba de su disciplina deportiva en la que han conseguido algún triunfo (4 en 2012 y 8 en 2016 ) que aquellas en las que posan mostrando la medalla o celebrando su triunfo (2 en 2012 y 4 en 2016). Sólo en una de 2016, la bandera de España está presente, cuando Ruth Beitia celebra su triunfo.

Si cuantificamos la especialidad de las deportistas que recibieron mayor cobertura en Londres 2012 y Río 2018 en Marca, vemos en las Fig. 3, 4 y 5 cómo los deportes en los que las deportistas consiguieron medalla recibieron un lógico mayor seguimiento informativo, no solo por el triunfo logrado sino porque participaron en más pruebas eliminatorias, hasta lograr un puesto en el pódium. En atletismo, aunque no lograron medalla en 2012, se registra un alto número de unidades informativas porque este deporte agrupa muchas disciplinas y porque ese año había expectativas de que Ruth Beitia en salto de altura y Marta Domínguez en carrera consiguieran medalla. El baloncesto femenino español es el deporte con mayor 
cobertura en 2016 (24 unidades informativas), dado que es un deporte que goza de un gran seguimiento por parte de la audiencia, la selección española obtuvo medalla de plata y reaparecía en unos Juegos Olímpicos, tras no clasificarse para participar en los de Londres 2012, de ahí que no se contabilicen unidades informativas en baloncesto en esa cita olímpica.

Fig. 3. Deportes sobre los que se informa en las unidades informativas en las que las protagonistas son las deportistas nacionales

\begin{tabular}{|l|c|c|l|c|c|}
\hline & 2012 & 2016 & & 2012 & 2016 \\
\hline Vela & $\mathbf{3 4}$ & $\mathbf{1 0}$ & Piragüismo: aguas abiertas & 2 & 5 \\
\hline Natación & 26 & $\mathbf{1 9}$ & Salto de altura & 1 & 1 \\
\hline Balonmano & 23 & $\mathbf{1 3}$ & Tenis & 1 & 3 \\
\hline Waterpolo & 19 & 5 & Tenis mesa & 1 & 0 \\
\hline Atletismo & 12 & 9 & Gimnasia artística & 1 \\
\hline Natación sincronizada & 12 & 6 & Varios deportes en la misma & 13 & 1 \\
\hline Voleibol playa & & & noticia & & 12 \\
\hline Piragüismo slalom & 6 & 0 & Badminton & & 24 \\
\hline Tiro olímpico (deportivo) & 5 & 2 & Baloncesto & & 1 \\
\hline Hípica (equitación) & 5 & 2 & Ciclismo BMX & & 2 \\
\hline Taekwondo & 4 & 0 & Futbol & & 3 \\
\hline Lucha grecorromana & 3 & 0 & Golf & & 3 \\
\hline Judo & 3 & 0 & Hockey hierba & 183 & 147 \\
\hline Ciclismo/pista & 3 & 4 & Remo & & 3 \\
\hline Gimnasia rítmica & 3 & 2 & Rugby & & 1 \\
\hline Halterofilia & 2 & 7 & Tiro & & 1 \\
\hline Natación aguas abiertas & 2 & 5 & Triatlón & & 1 \\
\hline TOTAL & & 1 & & & \\
\hline
\end{tabular}

Fuente: Elaboración propia 
Fig. 4. Medallero femenino España

\begin{tabular}{|l|l|}
\hline \multicolumn{2}{|c|}{ LONDRES 2012} \\
\hline VELA & \multicolumn{1}{|c|}{ Tamara Echegoyen / Ángela Pumariega/ Sofía Toro } \\
\hline Vela ligera Elliot 6 m (Match Race) & Marina Alabau \\
\hline Windsurf Rs:X & \multicolumn{2}{|c|}{ Medalla de plata } \\
\hline \multicolumn{2}{|c|}{} \\
\hline NATACIÓN & Mireia Belmonte \\
\hline 200 m mariposa & Mireia Belmonte \\
\hline 800 m libre & Ona Carbonell / Andrea Fuentes \\
\hline Sincronizada Dúo & Selección femenina \\
\hline WATERPOLO & Brígida Yagüe \\
\hline TAEKWONDO 49 kg Mosca Olímpico Ab & Medalla de bronce \\
\hline \multicolumn{2}{|c|}{ Selección femenina } \\
\hline BALONMANO & Maider Unda \\
\hline LUCHA OLÍMPICA Libre olímpica $72 \mathrm{~kg}$ & Equipo \\
\hline NATACIÓN Sincronizada equipo & Maialen Chourraut \\
\hline PIRAGUISMO Slalom K-1 &
\end{tabular}

\begin{tabular}{|l|l|}
\hline \multicolumn{2}{|c|}{ RÍO 2016} \\
\hline NATACIÓN 200 m mariposa & Mireia Belmonte \\
\hline PIRAGUISMO Slalom K1 & Maialen Chourraut \\
\hline BADMINTON & Carolina Martín \\
\hline ATLETISMO Salto de altura & Ruth Beitia \\
\hline \multicolumn{2}{|c|}{ Medalla de plata } \\
\hline BALONCESTO & Selección femenina \\
\hline GUIMNASIA RITMICA & Selección femenina \\
\hline TAEKWONDO Menos de 75 kg & Eva Calvo \\
\hline \multicolumn{2}{|c|}{ Medalla de bronce } \\
\hline NATACIÓN 400 m estilos & Mireia Belmonte \\
\hline HALTEROFILIA 75 KG. & Lidia Valentín \\
\hline
\end{tabular}

Fuente: Elaboración propia 
La importancia otorgada en la cobertura informativa de unos JJOO a los resultados obtenidos por las deportistas también se puede comprobar con la cuantificación temática de los titulares de las unidades informativas registradas. Los titulares de una crónica deportiva, tal y como afirma Néstor Hernández (2003:125), son instrumentos de concentración sémica y de apelación comunicativa. Su análisis, por tanto, aporta una visión de los asuntos que el diario considera relevantes respecto a una información. En los titulares de las unidades informativas sobre las deportistas nacionales (vid. Fig. 5), se comprueba que en más del 50\% se destacan, principalmente, los resultados de su participación.

Fig. 5. Tema de los titulares en las unidades informativas en las que las protagonistas son las deportistas españolas

\begin{tabular}{|l|c|c|}
\hline TEMA & 2012 & 2016 \\
\hline Éxitos, fracasos, clasificación y medallas & $92(50,3 \%)$ & $76(51.7 \%)$ \\
\hline Características físicas y mentales de la deportista & $17(9,3 \%)$ & $13(8.8 \%)$ \\
\hline Preparación y organización del equipo & $17(9,3 \%)$ & $12(8.2 \%)$ \\
\hline Cuestiones personales & $14(7,7 \%)$ & $14(9.5 \%)$ \\
\hline Prueba concreta & $7(3,8 \%)$ & $16(10.9 \%)$ \\
\hline Rivalidades directas & $4(2,2 \%)$ & $3(2 \%)$ \\
\hline Aspectos económicos del deporte de élite & $3(1.6 \%)$ & --- \\
\hline Carrera deportiva & $3(1.6 \%)$ & $6(4.1 \%)$ \\
\hline Villa olímpica: el día a día & $2(1.1 \%)$ & --- \\
\hline Salud & $1(0.5 \%)$ & $4(2.7 \%)$ \\
\hline Juegos Olímpicos: organización & $1(0.5 \%)$ & --- \\
\hline Juegos Olímpicos: cobertura mediática & $1(0.5 \%)$ & -- \\
\hline Otros & $21(11.5 \%)$ & $3(2 \%)$ \\
\hline TOTAL & 183 & 147 \\
\hline
\end{tabular}

Fuente: Elaboración propia

\section{Equipo femenino Elliot 8 y Carolina Marín: diferentes expectativas, diferentes coberturas}

Tamara Echegoyen, Sofía Toro y Ángela Pumariega, integrantes del equipo femenino de Match Race, llegaron a Weymouth a participar en los Juegos Olímpicos de Londres 2012, tal y como publica Marca el 8 de agosto, "sin ninguna presión" (p. 6). La igualdad y competencia enorme entre las tripulaciones participantes en esta prueba hacía impredecibles los pronósticos sobre su clasificación. Esto, junto con el hecho de que el equipo se formase en mayo del 2009 para participar en una clase nueva de embarcación para el Mach Race, el Elliot, hacía que, como indica el periodista Nacho Gómez el 12 de agosto, fuesen "hace sólo unos días, tres chavalas a las que nadie conocía por la calle" (p. 14). De ahí que su importancia informativa fuese creciendo conforme iban ganando posiciones tras cada regata. 
Por el contrario, las expectativas que se tenían al inicio de los Juegos Olímpicos de Río 2016 respecto a la actuación de la jugadora de bádminton Carolina Marín eran las más altas; la propia deportista declara en unas palabras suyas publicadas en la sección Parque Olímpico del cuadernillo de Marca del 9 de agosto, antes de iniciar la competición que "Es el torneo que mejor he preparado; no firmo otra medalla que no sea un oro" (p. 11). En Londres 2012 había sido eliminada en la fase de grupos tras perder contra la china Li Xuerui, ganadora de la medalla de oro de esos Juegos. Pero el 31 de agosto de 2014 derrotó a esta deportista en la final individual de los Campeonatos del Mundo de Badminton y se convirtió en la primera española en ganar un título mundial y la tercera jugadora europea en la consecución de la medalla de oro, después de Lene Koppen (1977) y Camilla Martin (1999). Con solo 21 años se convirtió en la campeona mundial más joven de Europa. Y tras diversos triunfos en distintos campeonatos y Superseries, en junio de 2015 consiguió ser la número uno mundial.

\subsection{Las 'chiquitas normales 'de Elliot 8 (Match Race)}

Los textos publicados sobre las primeras regatas del equipo femenino de Elliot 8 (2, 5, 6 y 8 de agosto), todos de menos de media página, inciden en los resultados, en una breve descripción de la regata realizada y en indicar cuál será la próxima confrontación tras ganar la prueba a la que se refiere la noticia. Pero no se hace referencia a las cualidades como deportistas de las integrantes del equipo. Tampoco las fotografías ofrecen información identificativa de las atletas: son planos generales de su embarcación durante algún momento de la regata. Lo que sí se señala es que las tres "siguen protagonizando la sorpresa más agradable para los intereses de España en el campo de regatas de Weymouth” (02/08/ p.18). De ahí que su importancia informativa fuese creciendo conforme iban ganando posiciones tras cada prueba.

No es hasta el 9 de agosto, ya clasificadas para la semifinal, cuando se publica una fotografía de plano entero de ellas con un amigo navegante portugués, y Tamara Echegoyen da alguna de las claves del éxito de su equipo: su tranquilidad y velocidad en popa. Y el 10 de agosto Marca dedica una página completa al equipo pluridisciplinar de vela. El reportaje describe la villa del equipo de vela y el día a día de los/as deportistas en ella. Resulta significativo de cómo las mujeres apenas son referentes del deporte de élite en 2012 el que, como muestra el reportaje, en la villa del equipo haya frases y fotografías motivadoras de gran tamaño de varios de los grandes ídolos del deporte nacional e internacional Pau Gasol, Rafa Nadal, Miguel Indurain, Alberto Contador, Usain Bolt o Mohammed Alí entre los que no se encuentra ninguna deportista.

El 11 de agosto, una vez que el equipo femenino de Elliot ya está en la final, el diario le dedica página y media, pero el protagonismo de los titulares, fotografías e información no lo acaparan las tres atletas: se lo lleva el tipo de embarcación (Elliot) y la canción con la que se activan cada jornada en los Juegos Olímpicos, anécdota sobre la que ya se había informado el día anterior.

\section{El barco fantasma}

Match Race. Tamara Echegoyen, Sofía Toro y Ángela Pumariega meten a España en la final de la clase más desconocida y etérea de la competición de vela. El Elliot 6 m nace y muere en estos Juegos de 2010.

El secreto de la vaina loca

Un vídeo de Van Damme con una base musical de reggaetón activa diariamente a nuestras medallistas 
Apenas se ofrecen datos sobre las deportistas; sólo unas líneas a su actuación en dos de las mangas. Y el texto comienza haciendo referencia a lo alucinada que se quedó Sofía Toro, seguidora del Déport, cuando recibió una llamada de móvil del jugador de ese club, Juan Carlos Valerón, felicitándola a ella y a sus compañeras por el rendimiento que estaban teniendo: "Tanto Sofía como sus compañeras Tamara Echegoyen y Ángela Pumairega van a tener que acostumbrarse a vivir experiencias similares [refiriéndose a la felicitación de Valerón] o mucho mejores a partir de ahora. Porque ayer confirmaron la hazaña de meterse en la finalísima de los Juegos Olímpicos", escribe el periodista (11/08 p. 18).

Como ganadoras de la medalla de oro, Tamara Echegoyen, Sofía Toro y Ángela Pumariega consiguen incrementar notablemente el espacio que les dedicaba Marca a 3 páginas, pero de nuevo, no acaparan directamente el protagonismo de los titulares: "El barco de plástico se convirtió en oro" (p. 12) "Un desafío a la física" (p. 13) y "La gorra de la suerte" (p. 14). Sólo lo logran en el perfil que Nacho Gómez escribe sobre ellas en esta última página con el titular: "Unas 'chiquitas' normales". Fotográficamente, sí que el protagonismo es para las tres deportistas: en una imagen aparecen en el podio con las medallas; en otra, están en un momento de la regata, pero siendo ellas el centro de atención visual de la imagen, no la embarcación, y una tercera fotografía de un plano medio de las tres celebrando el triunfo en la final olímpica.

Los titulares de las noticias que se publican durante todos los días que compiten se refieren a ellas a través o de sus apellidos y del país al que representan ("España está a un triunfo de las semifinales" 8/08 p. 6), por ejemplo, o como las chicas del match race, en lugar de identificarlas como "el equipo femenino del match race". Y se identifica la especialidad deportiva a la que se refiere la noticia incluida dentro de la sección Londres 2012 Vela a través del cintillo 'Match Race`. Aunque no hay equipo masculino español de esta modalidad, si se escribiese en el cintillo junto a 'Match Race' el adjetivo 'femenino', se ayudaría a visibilizar entre los lectores la participación de las atletas en esta disciplina. Y en otras, pues esta práctica periodística de incluir el género de la especialidad deportiva sobre la que se informa no se lleva a cabo con casi ningún deporte.

\subsection{El reinado deportivo e informativo de Carolina Marín y su entrenador}

Estar en el puesto más alto del ranking de las expectativas por lograr un oro olímpico hace que el espacio que se concede a la información sobre el bádminton femenino en Marca en los Juegos Olímpicos de Río 2016 sea mayor que el que se otorga a otros deportes, incluso a aquellos que logran finalmente el preciado metal. También provoca que la referencia a Carolina Marín como "campeona", "bicampeona”, o como "doble campeona del mundo" o "máxima favorita a hacerse con el oro" sea una constante en los textos que Marca publica sobre su actuación deportiva, Y que se refleje ese estatus de liderazgo que Marín ostenta en su disciplina en los titulares de las informaciones tras cada partido: "Carolina ejerce de número 1. Exhibición de la campeona del mundo ante la coreana Sung para logar el pase a semifinales” (17/08/p. 13); “Carolina acaricia el oro"(19/08 p. 9).

Asimismo, fotográficamente, el protagonismo se concede a medios planos que muestran a la deportista en un gesto característico suyo y muy ensayado: el brazo levantado y el puño enérgicamente cerrado mientras da un grito de rabia; así celebra cada punto: quiere que sus rivales visualicen que va a por todas. Y Marca presenta así a sus lectores a Marín en las imágenes que publica de ella. 
Este situarse en la "línea de salida" de la competición como favorita hace que Marca, ya antes del debut de Carolina Marín en Río, le dedique 5 columnas completas de la página 12, dos fotografías y se refiera a ella en el titular como la campeona ("Los secretos de la campeona"), y en el titular del despiece de esta manera: "La bicampeona mundial inicia hoy el camino hacia la triple corona" (11/08 p. 12).

No obstante, en ese primer texto del 11 de agosto, el periódico a quien concede el protagonismo es al entrenador de Marín, Fernando Rivas, al que le otorga el mérito de ser el que "ha fabricado con sus métodos una supercampeona mundial “, pues la clave del éxito de Carolina está en la innovación: "Mucho trabajo y la búsqueda continua de nuevas fórmulas. Fernando Rivas, de alguna manera, tiene su propio departamento de I+D del bádminton. De hecho, su fórmula de trabajo se ha convertido en referencia mundial". (11/08 p. 12).

El reportaje comienza refiriéndose a él: "Cada vez que Fernando Rivas le dice a Carolina: 'Se me ha ocurrido una idea. Vamos a probarla', la onubense tiembla” y se van desgranando a lo largo del reportaje los métodos originales de Rivas. En el texto y en el sumario, lo único que se dice de ella es que ha llorado en algún entrenamiento de lo duro que ha sido. Sólo es en el despiece donde se ensalza a la deportista, a través de estas palabras de su entrenador: "Carolina no es un talento natural sino que se ha forjado a base de trabajo. Es una campeona por su mentalidad ganadora que la hace diferente". Una fortaleza a la que de nuevo la periodista Almudena Rivera hace referencia el 20 de agosto una vez que Marín ya ha ganado el oro: "Una mente maravillosa” (Titular); “Motivación. La fortaleza mental de Carolina también se trabaja” (subtítulo). Es la principal cualidad que se destaca en los textos que Marca publica sobre ella: su mentalidad de trabajar duro para conseguir lo que se había propuesto: el oro olímpico. "Puedo porque pienso que puedo" es su lema.

El oro que se espera que consiga Marín no supone una medalla más ni para ella ni para España: supondría que la jugadora española consiguiera la triple "corona” en el bádminton, como campeona europea, mundial y olímpica. Y para España sería una medalla histórica por ser la primera medalla olímpica para el bádminton español pero, sobre todo, por ser la primera que conquista una jugadora no asiática. Y todo esto contribuye a que se dé importancia en las crónicas a sus rivales, en especial a la surcoreana Sung Ji Hyun y a la china Li Xuerui, y a que el triunfo de la deportista española se viva en clave de orgullo nacional. Así, el gran titular de la crónica sobre la final femenina de bádminton, que ocupa dos líneas, es "Carolina de España" (20/08/2016, p. 8) bajo una imagen a siete columnas de la deportista con los brazos abiertos sosteniendo una bandera de España.

Junto a esta imagen, en la siguiente columna, se publican tres fotografías de la deportista celebrando el triunfo, según el diario, a lo Nadal. "Carolina Marín siempre ha reconocido su admiración por el tenista. Ayer su celebración en la pista tras ganar el oro recordó a las del manacorí” (20/08 p. 9). Como ocurriera con los deportistas que son estímulo para el equipo de vela español, de nuevo es un atleta masculino el referente para los propios atletas. Y Marca lo resalta en su crónica.

Asimismo, junto a la crónica se edita un perfil sobre Fernando Rivas en el que, de nuevo, se resalta la importancia que el entrenador ha tenido en el triunfo de Marín y se le considera un referente:

Estudió métodos para conseguir el mejor rendimiento posible de Carolina, un diamante que ha pulido durante nueve años. Su forma de trabajar tan metódica, disciplinada y analítica, en la que cada detalle cuenta, es el secreto de que una española haya triunfado entre asiáticas y haya colocado a España en el mapamundi del bádminton. La innovación ha sido clave. También la falta de tradición. Se ha convertido en un referente". 
La actuación de Carolina en Río 2016 quizá pueda hacer que ella también sea un referente deportivo para la actual generación. Como indica la periodista Almudena Rivera en su crónica "Gracias a sus éxitos, España ha descubierto que el bádminton es mucho más que un deporte que se juega en el colegio o en la playa”. No obstante, las siguientes palabras de la periodista ponen de nuevo en relieve sólo a deportistas masculinos como referentes: "Su gesta [refiriéndose a Marín] está a la altura de pioneros de la talla de Manolo Santana en el tenis, Severiano Ballesteros en el golf o Ángel Nieto en motociclismo".

\section{Conclusiones}

El deportista de élite se convierte en héroe nacional, fuente de orgullo para su país y en modelo y referente deportivo principalmente cuando compite y gana una medalla; y en ello juegan un papel esencial los medios de comunicación, reforzadores de ese estatus mediante una amplia cobertura informativa de sus logros. Iniciamos esta investigación con el objetivo de comprobar si esto ocurrió con el deporte femenino español en las citas olímpicas de Londres 2012 y Río 2016, en las que las atletas consiguieron mejores resultados (más medallas) que sus homólogos masculinos.

Tras los análisis realizados se observa que el valor noticia del éxito deportivo contribuyó a que el diario Marca realizase una amplia cobertura de la actuación del sector femenino, centrada en los resultados obtenidos en las distintas pruebas y en la preparación de las deportistas. No obstante, en el tratamiento informativo del deporte femenino, por encima de la importancia del logro de una medalla, prima la conjunción del valor de la nacionalidad de la deportista unido al de las expectativas de éxito. Así, si en una prueba hay posibilidad de que las deportistas españolas logren medalla, se informa antes y de forma más extensa sobre su actuación, aunque finalmente no logren un puesto en el medallero, que de la medalla de oro conseguida por las atletas internacionales. Igualmente, las deportistas españolas son el centro de impacto visual de varias portadas de los suplementos, mientras que las atletas internacionales no consiguen protagonizar ninguna.

No sucede lo mismo, sin embargo, con el deporte masculino. El análisis de las portadas nos demuestra que, con independencia de cuál sea la nacionalidad del atleta, ellos aparecen en primera página porque ostentan la categoría de referentes deportivos. Y esto nos lleva a establecer la segunda conclusión: el estatus de héroe deportivo sigue siendo hegemónicamente masculino, tal y como afirmaban Giuliano et al en 2007. Si bien el análisis de contenido de los textos analizados nos permite afirmar que en esas coberturas informativas del deporte femenino no se trivializa a las deportistas acentuando su atractivo físico, sus rasgos de feminidad o sus vidas personales, como se pudiera observar antaño en algunos medios, el pódium de referente deportivo lo siguen ocupando ellos, aunque ellas logren mayor presencia en el pódium olímpico. Con su éxito deportivo, las atletas logran sumar metales al medallero español y subir el nivel de orgullo nacional durante la celebración de los Juegos Olímpicos. Pero, como se observa en la información realizada por Marca los días previos al inicio de los Juegos de Río 2016 y en el análisis de contenido de las crónicas sobre el equipo femenino de Elliot 8 y Carolina Marín, hasta para los propios deportistas, los modelos inspiradores siguen siendo atletas masculinos.

El análisis de contenido y la lectura crítica de la muestra de noticias seleccionada nos ha permitido constatar la asimetría de los valores informativos existente entre la cobertura de la actuación de las deportistas y la de los atletas. En futuras investigaciones resultaría pertinente completar y confrontar estos resultados con responsables y periodistas de diarios deportivos a través del empleo de herramientas metodológicas como las entrevistas en profundidad, los focus group o las encuestas. 


\section{Referencias bibliográficas}

Alfaro, E.; Bengoechea, M. \& Vázquez, B. (2010). Hablamos de deporte. En femenino y en masculino. Madrid: Instituto de la Mujer. Disponible en http://www.csd.gob.es/csd/estaticos/myd/hablamos_deporte.pdf

Alvesson, M. \& Willmott, H. (2003). Studying management critically. London: Sage.

Angulo, M. (2007). Las imágenes de las deportistas en los medios de comunicación. Consejo Superior de Deportes. Ministerio de Educación y Ciencia. España. Disponible en http://www.mujerydeporte.org/documentos/docs/articulo_ imagen_mujer_deportista_en_medios.pdf

Asociación para la Investigación de los Medios de Comunicación (AIMC). Estudio General de Medios. Disponible en https://www.aimc.es/egm/que-es-el-egm/

ASPIC-Comunicación para la Dirección de Juventud y Deportes del Gobierno Vasco (2015). Presencia y tratamiento del deporte femenino en la prensa generalista vasca y en periódicos de información deportiva. Euskadi: Dirección de Juventud y Deportes del Gobierno Vasco. Disponible en https://es.slideshare.net/Irekia/ estudio-presencia-mujer-deporte-global-castpara-webbaja?from_action=save

Birrell, S. (2000). Feminist theories for sport. In J. Coakley \& E. Dunning (Eds.), Women, sport, and culture (pp. 221-244). London: Sage.

Bissell, K.L. \&Duke,A.M. (2007). Bump, set, spike:An analysis of commentary and camera angles of women's beach volleyball during the 2004 Summer Olympics. Journal of Promotion Management, 13(1/2), 35-53.

Caspistegui, F. J. (2012). Deporte e identidad, o sobre cómo definirnos. Historia y Comunicación Social, 17, 19-39. Disponible en https://doi.org/10.5209/rev_HICS.2012.v17.40597

Centre for Gender Equality (2006). Sport, Media and Stereotypes Women and Men in Sports and Media. Iceland: Centre for Gender Quality. Disponible en http://www.mujerydeporte.org/documentos/docs/sms_summary_report.pdf

Cooky, C., Messner, M. A., Hextrum, R. H. (2013). Women play sport, but not on TV: A longitudinal study of televised news media. Communication \& Sport, 1 (3), 203-230. Disponible en https://doi.org/10.1177/2167479513476947

Crouse, K. (2013). Why Female Atlethes Remain on Sport's periphery. Communication \& Sport, 1 (3), 237-240. Disponible en https://doi.org/10.1177/2167479513487722

Daniels, D. B. (2009). Polygendered and ponytailed: The dilemma of femininity and the female athlete. Toronto: Canadian Scholars' Press Inc.

Duncan, M.C. \& Messner, M. (2005). Gender in televised sports: News and highlights shows, 1989-2004. Disponible en http://www.aafla.org/9arr/ResearchRe-ports/tv2004.pdf

Durántez, C. (2012). Los Juegos. Las Olimpiadas en la historia. Madrid: Edaf.

Fernández, A. \& Bassani, J.J. (2008). Deporte e identidad nacional en Brasil: negociaciones en torno a cuatro ídolos. Materiales para la Historia del Deporte, 6, 46-62. Disponible en https://www.upo.es/revistas/index.php/ materiales_historia_deporte/article/view/503 
Fink, J.S. \& Kensicki, L.J. (2002). An imperceptible difference: Visual and textual constructions of femininity in Sports Illustrated and Sports Illustrated for Women. Mass Communication \& Society, 5(3), 317-339.

García, M.R. (1983). Diseño y remodelación de periódicos. Pamplona: EUNSA.

Giuliano, T. A., Turner, K. L., Lundquist, J. C. \& Knight, J. L. (2007). Gender and the selection of public athletic role models. Journal of Sport Behavior, 30 (2), 161-198. Disponible en https://www.researchgate.net/ publication/285011948_Gender_and_the_selection_of_public_athletic_role_models

González-Ramallal, M.E.(2008). La identidad contada: la información deportiva en torno a la selección española de fútbol. Universitas Humanística, 66 (66), 219-238. Disponible en https://revistas.javeriana.edu.co/index.php/univhumanistica/ article/view/2107

Grau, S.L., Roselli, G., \& Taylor, C.R. (2007). Where's Tamika Catchings? A content analysis of female athlete endorsers in magazine advertisements. Journal of Current Issues and Research in Advertising, 29(1), 55-65.

Hoeber, L. (2007). Exploring the gaps between meanings and practices of gender equity in a sport organization. Gender, Work and Organization, 14(3), 259-280.

Humanez, E. (2014, Septiembre, 14): Deporte e identidad nacional: una mirada desde la euforia del Mundial de fútbol. Disponible en https://nmnoticias.ca/2014/09/14/deporte-e-identidad-nacional-una-mirada-desde-la-euforia-delmundial-de-futbol/

Jones, D. (2006). The representation of female athletes in online images of successive Olympic Games. Pacific Journalism Review,12(1), 108-129.

Kane, M.J. \& Maxwell, H. (2011). Expanding the Boundaries of Sport Media Research: Using Critical Theory to Explore Consumer Responses to Representations of Women's Sports. Journal of Sport Management, 25, 202-216.

Kim, E., Walkosz, B.J., \& Iverson, J. (2006). USA Today's coverage of the top women golfers, 1998-2001. The Howard Journal of Communications, 17, 307-321.

Knight, J. L. \& Giuliano, T. A. (2001) He's a Laker; She's a Looker: The Consequences of Gender Stereotypical Portrayals of Male and Female Athletes by the Print Media. Sex Roles, 45, 3-4, 217-229. Disponible en https://link.springer.com/ article/10.1023/A:1013553811620

Krippendorff, K. (2018). Content Analysis: An Introduction to Its Methodology (4th ed.). SAGE.

Lallana, I. (2005). La mujer y los Juegos Olímpicos: análisis a través de los medios de comunicación. Retos para Beijing 2008. Disponible en https://core.ac.uk/download/pdf/13282883.pdf

Mateos, C., Martínez, M. J. \& Rodríguez, D. (2005). Identidad y estereotipos de la mujer en el deporte. Una aproximación a la evolución histórica. Revista de Investigación en Educación, 2, 109-126.

Meneses, J.A. (2008). El futbol nos une: socialización, ritual e identidad en torno al futbol. Culturales, 4 (8), 101-140. Disponible en http://culturales.uabc.mx/index.php/Culturales/article/view/68/67 
Méndez-Giménez, A., Fernández-Rio, FJ. \& González, C. (2008). El deportista de élite: influencias positivas y negativas en la población infantil y adolescente. Tandem. Didáctica de la educación física, 28, 6-16. Disponible https://www. researchgate.net/publication/236230985_El_deportista_de_elite_influencias_positivas_y_negativas_en_la_poblacion_ infantil_y_adolescente

Moragas, M. (2000). Olimpismo, comunicación y cultura. Barcelona: Centre d'Estudis Olímpics UAB Disponible en https://core.ac.uk/download/pdf/13282865.pdf

Ramallal, M. (2003). Sociedad y deporte: análisis del deporte en la sociedad y su reflejo en los medios de comunicación en España. Disponible en http://www.fes-web.org/uploads/files/res/res04/12.pdf

Sainz de Baranda, C. (2013). Mujeres y deporte en los medios de comunicación. Estudio de la prensa deportiva española (1979-2010). Disponible en http://hdl.handle.net/10016/16505

Sanz, B. (Coord.) (2015). Las mujeres deportistas en la prensa: los Juegos Olímpicos de Londres 2012. Barcelona: UOC.

Shaller, J. (2006). Female Athletes in the Media: Under Representation and Inadequacy. The Review: A Journal of Undergraduate Student Research, 8, 50-55. Disponible en https://core.ac.uk/download/pdf/48615056.pdf

Van Dijk, T. A. (1999). El análisis crítico del discurso. Anthropos, 186, 23-36. Disponible en http://www.discursos.org/ oldarticles/El\%20an\%E1lisis\%20cr\%EDtico\%20del\%20discurso.pdf 
